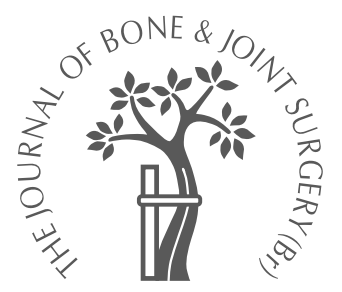

A. A. Jafri,

S. M. Green, P. F. Partington,

A. W. McCaskie, S. D. Muller

From the University of Newcastle upon Tyne, Newcastle upon Tyne, England

A. A. Jafri, BSc, MRCS, Clinical and Research Fellow A. W. McCaskie, FRCS (Tr \& Orth), Professor of Orthopaedics

S. D. Muller, MD, Specialist Registrar

P. F. Partington, FRCS ( $\operatorname{Tr} \&$ Orth), Consultant

Orthopaedic Surgeon Wansbeck General Hospital, Woodhorn Lane, Ashington, Northumberland NE63 9JJ, UK.

S. M. Green, PhD, Lecturer School of Engineering, University of Durham, South Road, Durham DH1 3LE, UK.

Correspondence should be sent to Mr A. A. Jafri at Department of Orthopaedic Surgery, Medical School, Framlington Place, University of Newcastle upon Tyne, Newcastle upon Tyne NE2 4BN, UK.

(C) 2004 British Editorial Society of Bone and Joint Surgery doi:10.1302/0301-620X.86B8. $14660 \$ 2.00$

$J$ Bone Joint Surg $[\mathrm{Br}]$ 2004;86-B:1214-19.

Received 2 June 2003;

Accepted after revision

15 January 2004

\title{
Pre-heating of components in cemented total hip arthroplasty
}

Fatigue fractures which originate at stress-concentrating voids located at the implantcement interface are a potential cause of septic loosening of cemented femoral components. Heating of the component to $44^{\circ} \mathrm{C}$ is known to reduce the porosity of the cement-prosthesis interface.

The temperature of the cement-bone interface was recorded intra-operatively as $32.3^{\circ} \mathrm{C}$. A simulated femoral model was devised to study the effect of heating of the component on the implant-cement interface.

Heating of the implant and vacuum mixing have a synergistic effect on the porosity of the implant-cement interface, and heating also reverses the gradients of microhardness in the mantle.

Heating of the implant also reduces porosity at the interface depending on the temperature. A minimum difference in temperature between the implant and the bone of $3^{\circ} \mathrm{C}$ was required to produce this effect. The optimal difference was $7^{\circ} \mathrm{C}$, representing a balance between maximal reduction of porosity and an increased risk of thermal injury. Using contemporary cementing techniques, heating the implant to $40^{\circ} \mathrm{C}$ is recommended to produce an optimum effect.

Aseptic loosening remains the most common long-term complication of cemented total hip arthroplasty. ${ }^{1}$ Debonding and fatigue fractures originating at the implant-cement interface have been implicated in loosening. ${ }^{2-5}$ This interface has been identified as the region of the highest peak stresses in the mantle. Voids which are located in this region may predispose to the initiation and propagation of fatigue fractures by acting as stress concentrators. $^{2,6-8}$ Pre-coating the femoral stem with a thin layer of highly polymerised polymethylmethacrylate improves the shear strength of the cement-stem interface, ${ }^{9,10}$ but increased stresses across the cement-bone interface may predispose to early failure at this site. ${ }^{11,12}$ Increased roughness of the surface of the stem also enhances the initial shear strength of the implant-cement interface. However, if debonding does occur, large amounts of cement and metal particulate debris may be generated. ${ }^{13,14}$

Dall, Miles and Juby ${ }^{15}$ initially suggested pre-heating the femoral component as a means of accelerating polymerisation of the cement. Bishop, Ferguson and Tepic ${ }^{16}$ noted that preheating the femoral stem to $44^{\circ} \mathrm{C}$ reduced the porosity of the cement-stem interface. This is thought to result from the initiation of poly- merisation at the warmer interface. The technique has not been widely adopted because of concern about the increased risk of thermal osteonecrosis due to the higher temperatures, although Bishop et a $1^{16}$ identified no significant increase in temperature at the cement-bone interface after heating the component.

The recommendation that the femoral component be heated to $44^{\circ} \mathrm{C}$ before insertion was based upon experiments which assumed that the bone interface is at normal body temperature. ${ }^{16,17}$ We believe this to be incorrect. After exposure of the canal, reaming, lavage with saline at room temperature and thorough drying we consider that the temperature of the cement-bone interface is less than $37^{\circ} \mathrm{C}$.

Our study aimed to explore the effects of heating of the component on the implantcement interface and to investigate the interaction of the technique used for mixing the cement and heating of the component on the porosity of the interface. We also examined the circumstances by which this technique could be employed in clinical practice. By determining the temperature of the cement-bone interface, we can decide the temperature to which the prosthesis must be heated in order to achieve reduced porosity at the interface. 


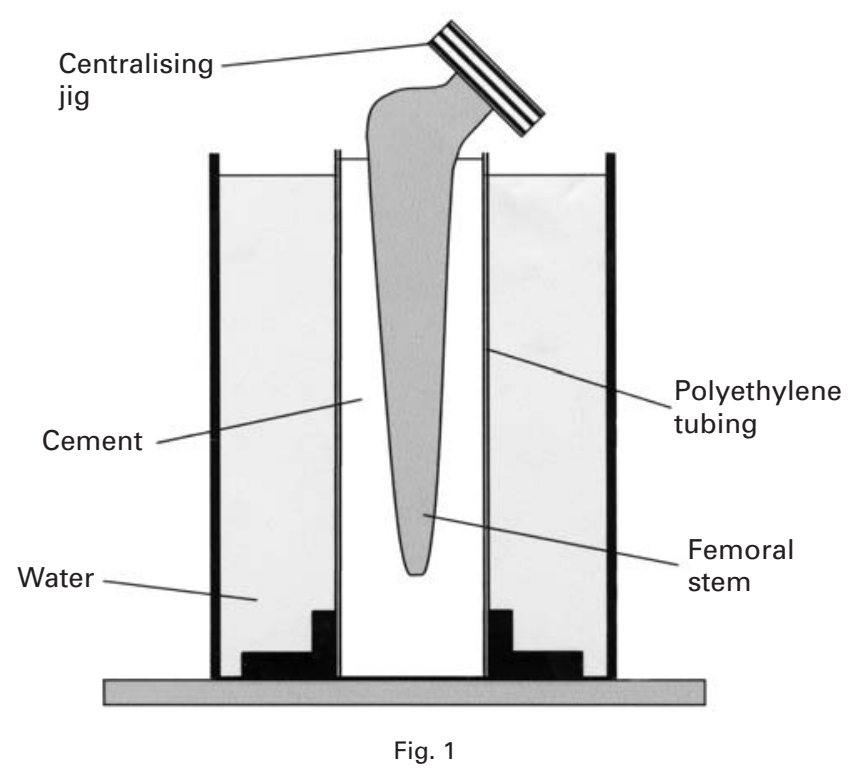

Diagram of the simulated femoral model.

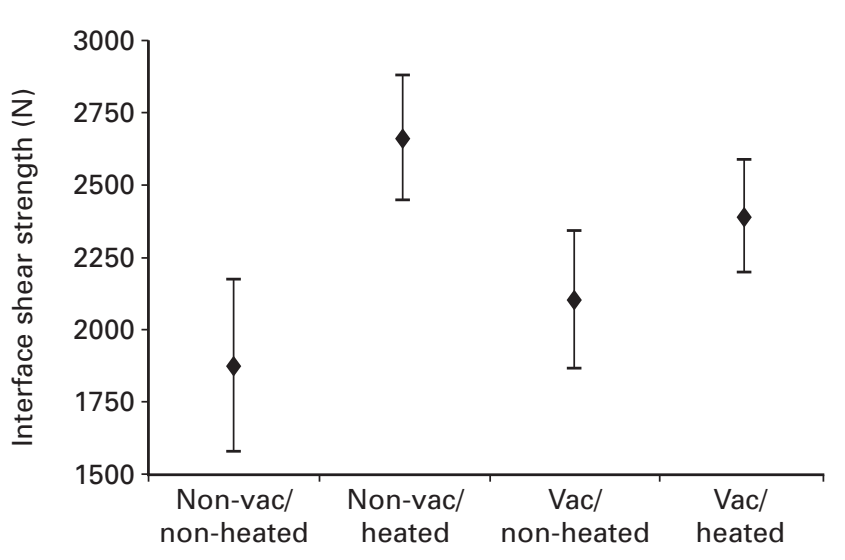

Fig. 2

Graph showing the strength of pull-out of the implant.

\section{Materials and Methods}

We developed a simulated model which allowed the temperature of the cement interfaces to be controlled. Polyethylene tubes, $19 \mathrm{~mm}$ in diameter and $10 \mathrm{~cm}$ in length were secured vertically in a water bath (Fig. 1). The arrangement was such that the lower ends of the tubes were watertight, and the tubes therefore remained dry. A custom-made jig was manufactured to insert femoral stems to a predetermined depth with the tip $1 \mathrm{~cm}$ above the base of the tube and at a predetermined rate of $1.67 \mathrm{~cm}$ per second using a Lloyd universal testing machine (Forum House, Hampshire, UK).
The femoral stems were preheated in a water-bath. Before assembly in the jig and insertion into the cement, they were thoroughly dried. This process took approximately 60 seconds. Experiments examining cooling over 60 seconds showed that the stem required overheating by $3^{\circ} \mathrm{C}$ to produce the desired temperature at insertion.

This equipment was used to perform two sets of experiments.

Experiment 1. The effect of heating the component and vacuum mixing on the properties at the interface was examined using 32 Elite femoral stems (Depuy Ltd, Leeds, UK). CMW1 (CMW, Depuy Ltd) cement was prepared using the Vacumix plus system (CMW, Depuy Ltd) according to the instructions of the manufacturers. Non-vacuummixed cement was prepared in the same manner without connection to the vacuum pump. The water bath was set at $37^{\circ} \mathrm{C}$ as in previous studies. ${ }^{16,17}$ Equal numbers of identical components were tested at room temperature and at $44^{\circ} \mathrm{C}$. There were four possible combinations of vacuum mixing and component heating. Each was repeated eight times.

Each mantle was then examined by performing a stem pull-out test to assess the extraction shear strength at the cement-stem interface. The mantles were then sectioned transversely into eight sections (Isomet 2000; Buehler Ltd, Lake Bluff, Illinois). Testing for indentation resistance was performed using a Mituyo semi-automated microhardness tester at three locations across the mantle adjacent to the stem, the mid region and in the periphery in three separate radians.

The transverse sections were then sectioned vertically to expose the implant-cement interface, producing 16 hemisections per mantle. This was examined by SEM and the results analysed using Student's $t$-test.

Experiment 2. There were two parts. In the first, the temperature in the femoral canal was determined in six patients. In the second, the affect of heating of the femoral prosthesis on the porosity of the cement was measured in the laboratory. The temperature of the cement-bone interface after preparing the canal before insertion of the cement, was determined in six patients undergoing primary total hip arthroplasty. We used a sterile, single-use, flexible, end-recording, calibrated thermocouple, which is commonly employed in monitoring critically ill patients in the intensive-care unit. The calibration was verified by means of a water bath with a set temperature and a mercury thermometer accurate to $0.1^{\circ} \mathrm{C}$.

The thermocouple was placed on the surface of the bone interface at the midpoint of the canal after standard preparation involving reaming and pulsatile lavage, before packing the medullary canal with surgical gauze to facilitate drying. This was left in situ during preparation of the cement. Immediately before inserting the cement the temperature was recorded and the probe removed. A mean temperature of $32.35^{\circ} \mathrm{C}(95 \%$ confidence interval (CI) 29.6 to 35.0 ) was recorded. 


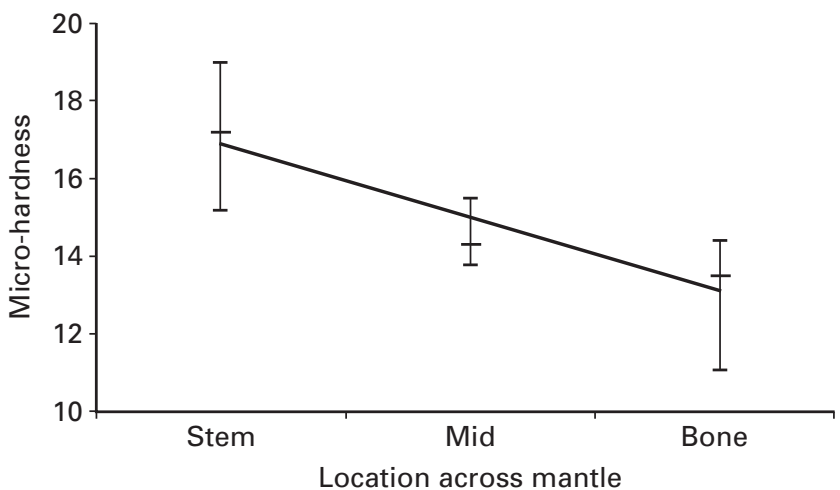

Fig. 3a

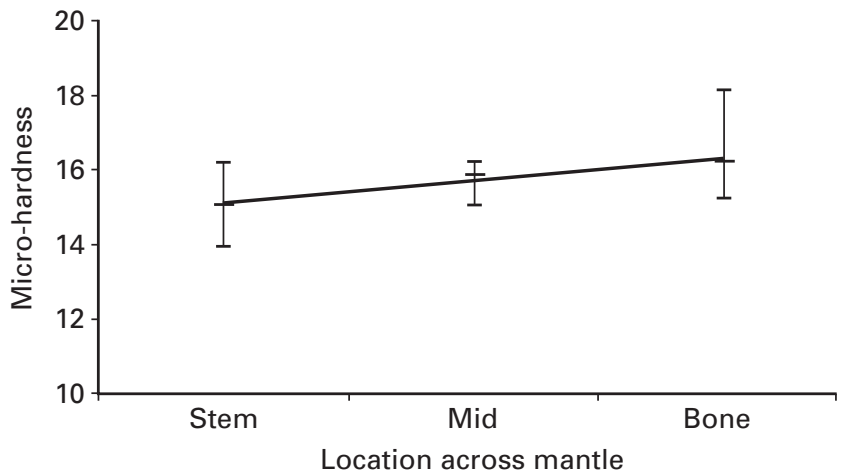

Fig. $3 b$

Graph showing the mean microhardness (with maximum and minimum values) a) with a heated component at $44^{\circ} \mathrm{C}$ and b) with the component at room temperature.

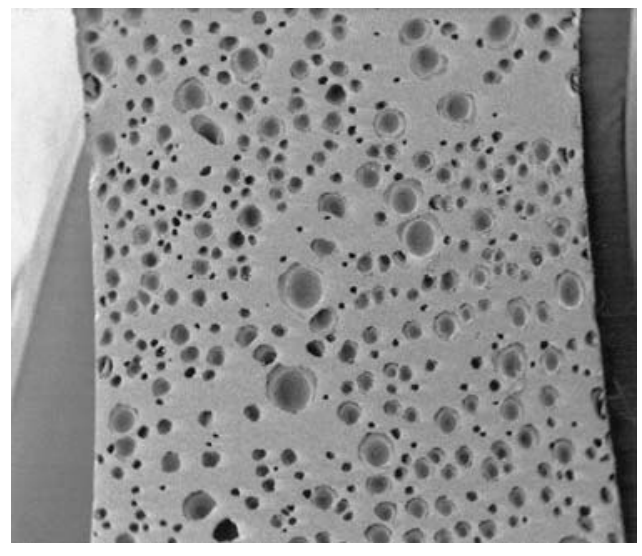

a

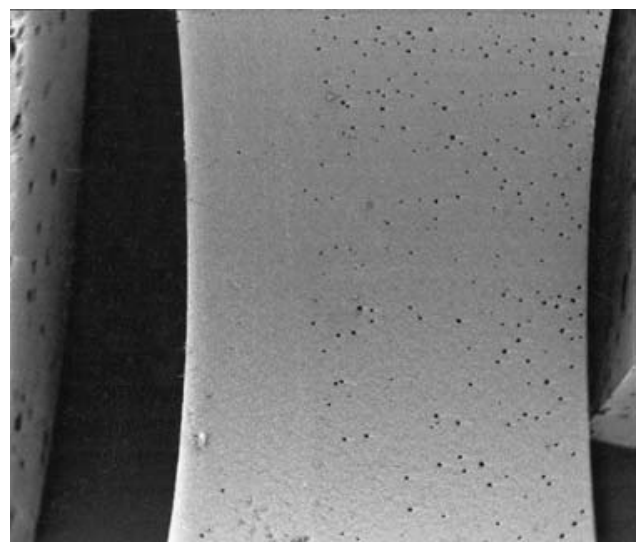

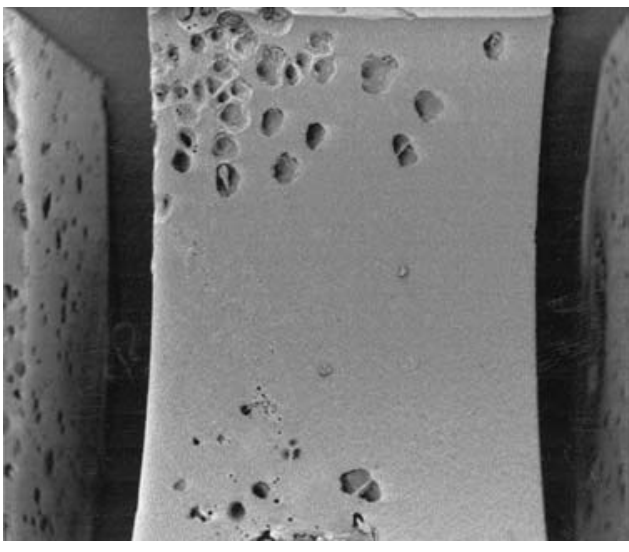

b

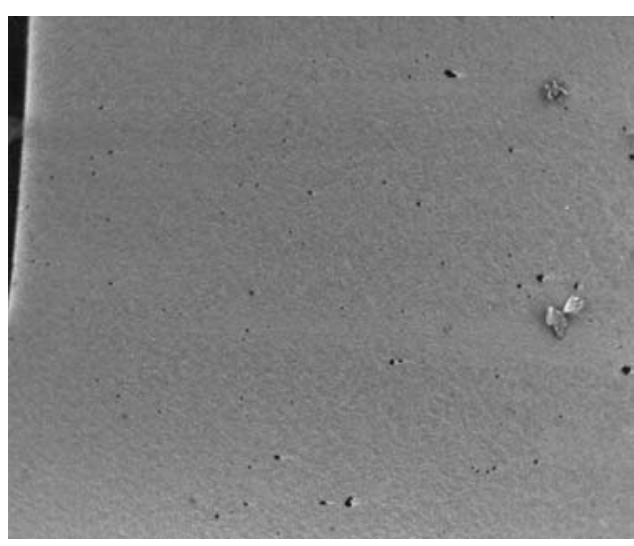

d

Fig. 4

Photomicrographs of the implant-cement interface a) with non-vacuum-mixed cement, room temperature component; b) vacuum-mixed cement, room temperature component; c) non-vacuum-mixed cement, heated component and d) vacuum-mixed cement, heated component.

The effect of heating the femoral component on the distribution of voids throughout the mantle was easier to see if the voids were not removed by prior vacuum mix- ing. A second experiment was therefore undertaken using cement which had not been vacuum mixed. The temperature of the water bath was set to $32^{\circ} \mathrm{C}$. Exeter stems 

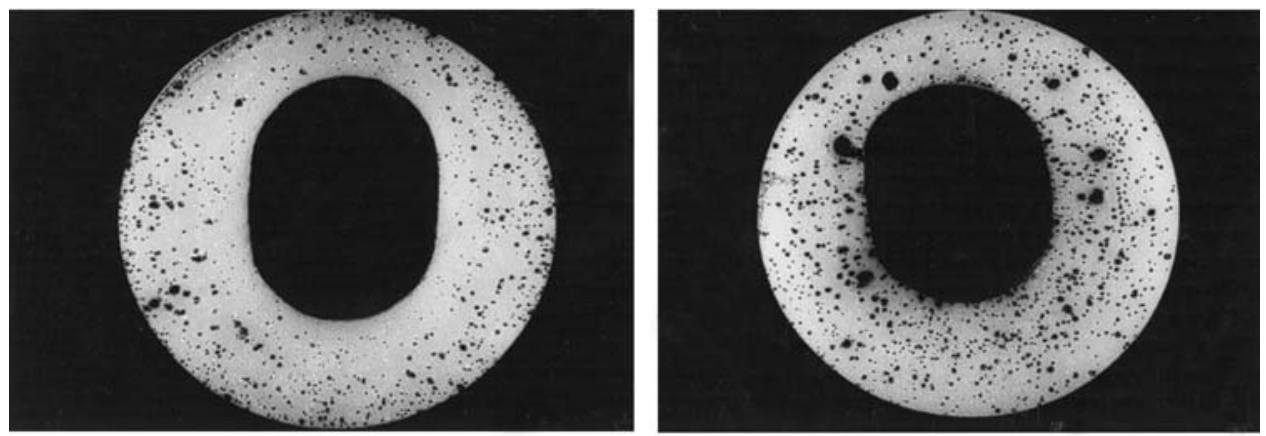

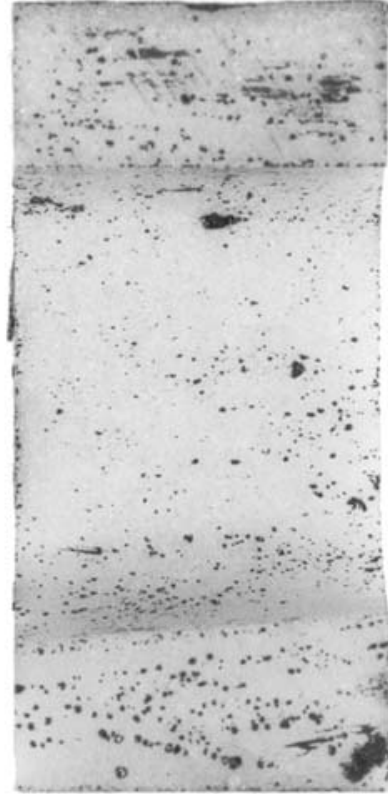

Fig. $5 a$

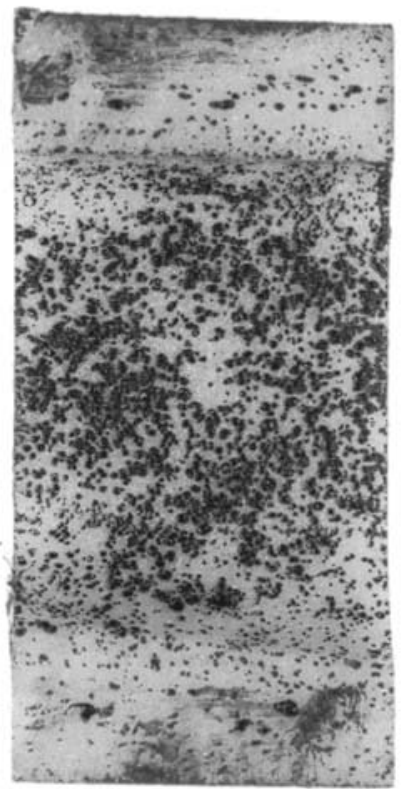

Fig. $5 b$

Photographs showing transverse sections and the exposed implant-cement interface with a) a heated component at $40^{\circ} \mathrm{C}$ and b) a component at room temperature.

(Stryker Howmedica Ltd, Newbury, UK) were heated to insertion temperatures of room temperature $\left(18^{\circ} \mathrm{C}\right)$, $32^{\circ} \mathrm{C}, 35^{\circ} \mathrm{C}, 37^{\circ} \mathrm{C}, 40^{\circ} \mathrm{C}$ and $44^{\circ} \mathrm{C}$. The stems were inserted four minutes after the onset of non-vacuum mixing of Palacos cement (Schering-Plough Ltd, Suffolk, UK).

After the cement had set, the stems were extracted and the mantles sectioned as in experiment 1 . The exposed cement-stem interfaces were prepared using a black acrylic stain and examined using Omnimet 3 (Beuhler) image analysis to assess the porosity of the interface by area percentage. Three mantles were examined for each temperature. They were cut into four transverse sections and divided vertically to give eight hemisections. A total of 24 sections were analysed for each temperature. Measurements of porosity were made and Student's $t$-test used for statistical analysis.

\section{Results}

Experiment 1. The ultimate shear strength of the interface for each group is shown in Figure 2. No attempt was made to calculate shear stress at the interface since the taper of the stem would render comparison with established data for vertical interfaces invalid. The observations allowed only direct comparison between specimens and thus demonstrated the effect of the techniques under investigation. Heating of the component increased the mean strength of interface shear by $534.6 \mathrm{~N}(27 \%$; p < 0.001). Vacuum mixing did not significantly increase shear strength.

Indentation to assess microhardness showed a gradient of hardness across the mantle. The warmest interface was consistently harder than the cooler area (Fig. 3). There was a large variability between specimens and statistical significance was not achieved. The heated components produced a mean difference in hardness of -2.31 (SD 1.26). Calcula- 


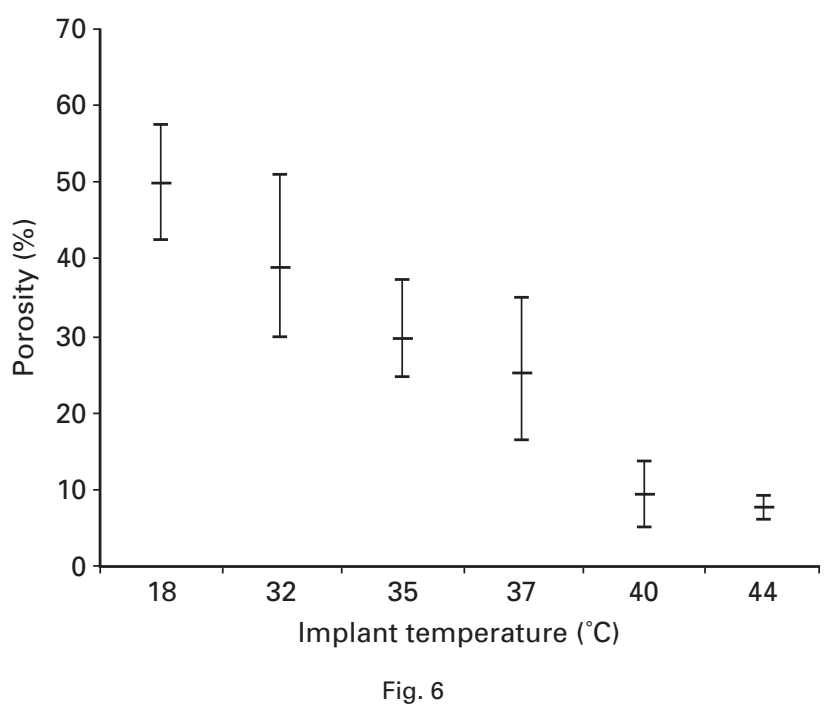

Graph showing implant temperature vs mean porosity of the implant-cement interface $(95 \% \mathrm{Cl})$.

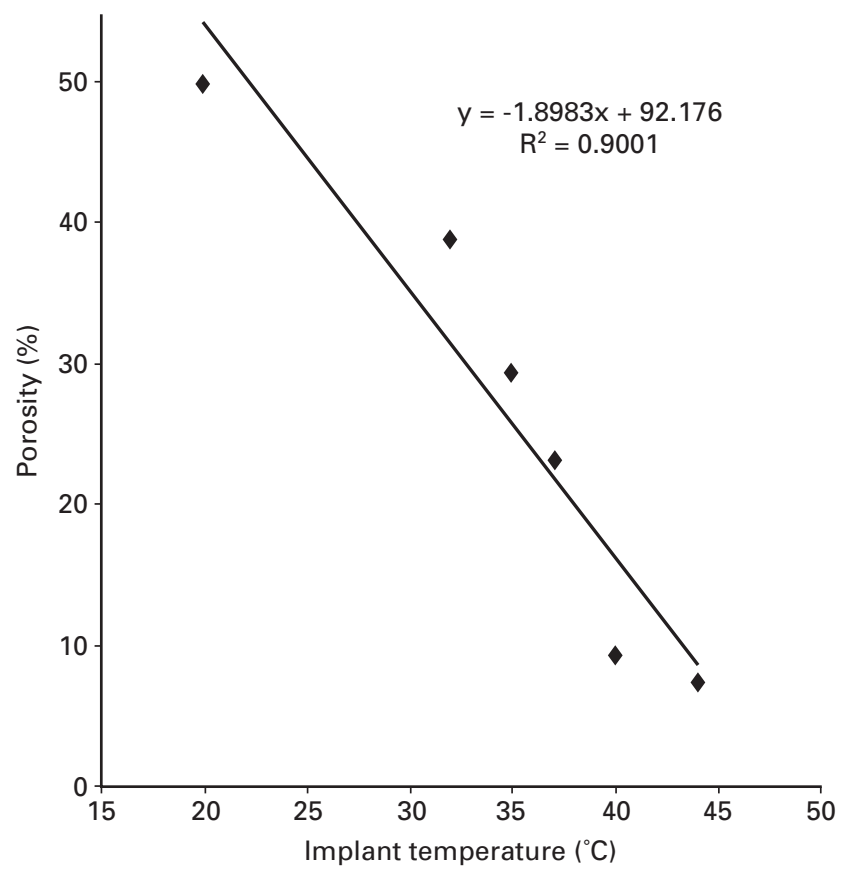

Fig. 7

Linear regression analysis for temperature of the implant and porosity of the interface.

tion of the absolute difference in microhardness across each mantle produced a figure which was unaffected by variability between specimens. At room temperature components produced a mean difference in hardness of +3.07 (SD 1.16) $(\mathrm{p}<0.0001)$. Analysis of this data by Student's $t$-test yielded a highly significant effect of heating of the compo-
Table I. The temperature of the implant $\left({ }^{\circ} \mathrm{C}\right)$, the mean percentage porosity and $95 \% \mathrm{Cl}$

\begin{tabular}{lll}
\hline Implant temperature $\left({ }^{\circ} \mathbf{C}\right)$ & Mean porosity (\%) & $\mathbf{9 5 \%} \mathbf{C l}$ \\
\hline 18 & 49.9 & 42.5 to 57.3 \\
32 & 38.9 & 29.6 to 48.2 \\
35 & 29.4 & 21.6 to 37.2 \\
37 & 23.1 & 16.4 to 29.8 \\
40 & 9.4 & 5.3 to 13.5 \\
44 & 7.5 & 6.2 to 8.8 \\
\hline
\end{tabular}

nent $(\mathrm{p}<0.001)$. Vacuum mixing had no effect on the gradient of hardness in either heated or non-heated components (Student's $t$-test, $\mathrm{p}=0.16$ and 0.76 , respectively).

Figures 4 and 5 show representative images on electron microscopy of the implant-cement interface. The mantles of non-vacuum-mixed components at room temperature showed large voids distributed throughout the interface. In those with vacuum mixed cement at room temperature the mantles contained interface voids of similar dimensions to non-vacuum mixed specimens, but they were fewer in number. Heating appeared to eliminate interfacial voids, but on closer inspection small voids could be identified. A combination of vacuum mixing and component heating produced an implant-cement interface with very few voids and these were very small.

Experiment 2. The mean interface porosity, SDs and 95\% CIs were calculated for each temperature of the implant (Figs 6 and 7). At room temperature the components showed a mean porosity at the interface of $49.9 \%$, whereas at $44^{\circ} \mathrm{C}$ this was $7.5 \%$. We performed a linear regression analysis (Fig. 7; Table I), which suggested that there was a close relationship between the magnitude of the temperature difference across the cement and the porosity at the interface.

There were no significant differences in porosity at the interface between implants at room temperature and those heated to $32^{\circ} \mathrm{C}(\mathrm{p}=0.102)$. It was necessary to heat the implant to $35^{\circ} \mathrm{C}$ before a significant effect could be detected $(\mathrm{p}<0.001)$ and porosity was reduced further when the implant was heated to $40^{\circ} \mathrm{C}$.

No further significant change occurred by heating to $44^{\circ} \mathrm{C}(\mathrm{p}=0.34)$. The effect on porosity by heating to the various temperatures is shown in Table II.

\section{Discussion}

Our study has confirmed the effect of pre-heating the femoral component on the porosity at the cement-stem interface. Reduction in porosity increased the surface area of stem-cement contact which was reflected in an increase of $27 \%$ in shear strength on extraction. This did not represent the clinical circumstance since the cement-stem interface was loaded in axial compression shear in vivo rather than in extraction tensile shear. However, the increase reflected the increased area of surface contact of the interface, and complemented its appearance on SEM.

Vacuum mixing was shown to reduce the number of voids at the cement-stem interface, but had little effect on 
Table II. The effect of heating $\left({ }^{\circ} \mathrm{C}\right)$ on the porosity of the interface

\begin{tabular}{lll}
\hline Implant temperature $\left({ }^{\circ} \mathrm{C}\right)$ & Effect on porosity $(\%)$ & $\mathbf{p}$ value \\
\hline 32 & -13 & 0.102 \\
35 & -21 & 0.0009 \\
37 & -25 & $<0.0001$ \\
40 & -37 & $<0.0001$ \\
44 & -36 & $<0.0001$ \\
\hline
\end{tabular}

the dimensions of the remaining voids. Heating the implant appeared to restrict expansion of the voids at the stem interface. This could be explained by earlier completion of polymerisation at the warmer interface before significant voids appeared. The latter could not expand in solidified cement. A combination of vacuum mixing and component heating produced a void-free cement-stem interface.

The detection of a gradient in microhardness was unexpected. The warmer interface consistently appeared harder than the cooler surface and paralleled the appearance of voids across the mantle. Previous work regarding the evolution of voids has suggested that they expand primarily by temperature-dependent, pressure-driven expansion caused by evaporation of monomer into existing trapped air voids. ${ }^{18}$ This process may be augmented by volumetric contraction of the cement. Voids may therefore act as depots of monomer leading to incomplete polymerisation of the surrounding cement. Reduced chain length, and consequent reduced steric hindrance, will alter the mechanical properties of the cement in the immediate region of the void. This may well be reflected in the gradient of hardness between areas of low and high porosity.

Previous studies reporting the effect of heating of the component on the cement-stem interface used vacuummixed cement. These did not maximise the ability to detect the effects of heating of the component on voids within the cement mantle. We used non-vacuum-mixed cement in our second experiment in order to produce a mixture containing numerous voids which allowed the effect of heating of the component to be more easily seen.

There is little information regarding the temperature of the cancellous bony bed before cementation. All previous work has been based on the assumption that the temperature of bone is the same as normal body temperature. Preparation of the canal and high-volume pulsatile lavage with fluid at room temperature may significantly reduce the temperature of the bone and lavage with chilled or iced fluids as a haemostatic measure will cool it even further.

There are conflicting reports concerning the impact of heated femoral components on the peak cement-bone temperature. Bishop et $\mathrm{al}^{16}$ found no significant increase, but Iesaka et $\mathrm{al}^{17}$ detected a rise of $6^{\circ} \mathrm{C}$ in peak temperature with pre-heated components. Conversely, cooling the implant reduced the interface peak temperatures by $7^{\circ} \mathrm{C} .{ }^{19}$ On balance it would appear that the initial temperature of the prosthesis influences the temperature of the bone interface.
There are concerns that heating the femoral stem will give an increased risk of thermal osteonecrosis. Lower initial bone temperatures and lower temperatures of preheated implants lessen this risk. The purpose of the second experiment was to determine the minimal temperature to which the prosthesis must be pre-heated in order to maximise the effect on interface porosity but to minimise the risk of thermal injury. A temperature difference between the bone and stem of $3^{\circ} \mathrm{C}$ appears to reduce significantly porosity at the interface but the maximal effect is obtained with a difference of $7^{\circ} \mathrm{C}$ across the mantle.

We have demonstrated the effect of pre-heating of the implant to various temperatures. Reduction of the voids in the high stress zone of the mantle immediately adjacent to the prosthesis is desirable. Heating the component and vacuum mixing appear to have complementary effects at the cement-stem interface. When using contemporary techniques of cementation with pulsatile lavage, preheating the implant to $40^{\circ} \mathrm{C}$ is recommended.

No benefits in any form have been received or will be received from a commercial party related directly or indirectly to the subject of this article.

\section{References}

1. Malchau H, Herberts P, Eisler T, Garellick G, Soderman P. The Swedish Total Hip Replacement Register. J Bone Joint Surg [Am] 2002;84-A(Suppl 2):2-20.

2. Raab S, Ahmed AM, Provan JW. The quasi static and fatigue performance of the implant/bone-cement interface. J Biomed Mater Res 1981;15:159-82.

3. Topoleski LDT, Ducheyne P, Cuckler JM. Micro-structural pathway of fracture in poly (methacrylate) bone cement. Biomaterials 1993;14:1165-72

4. Jasty M, Maloney WJ, Bragdon CR, et al. The initiation of failure in cemented femoral components. J Bone Joint Surg [Br] 1991;73-B:551-8.

5. Gruen TA, McNeice GM, Amstutz HC. "Modes of failure" on cemented stem-type femoral components. Clin Orthop 1979;141:17-27

6. Estok DM, Orr TE, Harris WH. Factors affecting cement strains near the tip of a cemented femoral component. J Arthroplasty 1997;12:40-8.

7. Lee IY, Skinner HB, Keyak JH. The effect of variation of prosthesis size on cement stress at the tip of a femoral component. J Biomech Mat Res 1994;28:1055-60.

8. Harrigan TP, Harris WH. A three dimensional non-linear finite element study of the effect of cement-prosthesis of debonding in cemented femoral total hip components. J Biomech 1991;24:1047-58.

9. Davies JP, Singer G, Harris WH. The effect of a thin coating of polymethylmethacrylate on the torsional fatigue strength of the cement-metal interface. Clin Jour Appl Biomater 1992:3:45-9.

10. Davies JP, Harris WH. Strength of cement-metal interfaces in fatigue: comparison of smooth, porous and pre-coated specimens. Clin Mater 1993;12:121-6.

11. Brown EC 3rd, Lachiewicz PF. Precoated femoral component in total hip arthroplasty: results 5-9 year follow-up. Clin Orthop 1999;364:153-9.

12. Gardiner RC, Hozack WJ. Failure of the cement-bone interface: a consequence of increasing the cement-prosthesis interface? J Bone Joint Surg [Br] 1994;76-B:49-52.

13. Crowninshield RD, Jennings JD, Laurent ML, Maloney WJ. Cemented femoral component surface mechanics. Clin Orthop 1998;355:90-102.

14. Shmalzried TP, Zahiri CA, Woolson ST. The significance of stem-cement loosening of grit blasted femoral components. Orthopaedics 2000;23:1157-64.

15. Dall DM, Miles AW, Juby G. Accelerated polymerisation of acrylic bone cement using preheated implants. Clin Orthop 1986;211:148-50.

16. Bishop NE, Ferguson S, Tepic S. Porosity reduction in bone cement at the cement stem interface. J Bone Joint Surg [Br] 1996;78-B:349-56.

17. lesaka K, Jaffe WL, Kummer FJ. Effects of pre-heating of hip prostheses on the stem-cement interface. J Bone Joint Surg [Am]2003;85-A:421-7.

18. Muller SD, Green SM, McCaskie AW. The dynamic volume changes of polymerising polymethylmethacrylate bone cement. Acta Orthop Scand 2002;73:684-7.

19. Rodop 0, Kiral A, Arpacioglu 0, et al. Effects of stem design and pre-cooling prostheses on the heat generated by bone cement in an in vitro model. J Int Med Res 2002;30:265-70. 